\title{
TIME-LAPSE MODELING AND INVERSION OF CO2 SATURATION FOR SEQUESTRATION AND ENHANCED OIL RECOVERY
}

Quarterly Report for the Period October 1, 2004 - December 31, 2004

Date Issued: February 18, 2005

\author{
Mark A. Meadows \\ 4TH WAVE IMAGING CORPORATION \\ 16A Journey, Suite 200 \\ Aliso Viejo, California 92656
}

PREPARED FOR THE U.S. DEPARTMENT OF ENERGY

NATIONAL ENERGY TECHNOLOGY LABORATORY

Work Performed Under DOE Award Number DE-FC26-03NT15417 


\section{FULL LEGAL DISCLAIMER}

This report was prepared as an account of work sponsored by an agency of the United States Government. Neither the United States Government nor any agency thereof, nor any of their employees, makes any warranty, express or implied, or assumes any legal liability or responsibility for the accuracy, completeness, or usefulness of any information, apparatus, product, or process disclosed, or represents that its use would not infringe privately owned rights. Reference herein to any specific commercial product, process, or service by trade name, trademark, manufacturer, or otherwise does not necessarily constitute or imply its endorsement, recommendation, or favoring by the United States Government or any agency thereof. The views and opinions of authors expressed herein do not necessarily state or reflect those of the United States Government or any agency thereof. 


\begin{abstract}
In the fifth quarter of this DOE NETL project, we have implemented an algorithm that inverts for changes in fluid properties over time using time-lapse seismic anomalies. This algorithm constitutes the second step in the inversion procedure for Phase III of our project. We demonstrate this inversion procedure with a synthetic data example. Additional activities in this reporting period include a trip by the Principal Investigator to an International Monitoring Workshop sponsored by the IEA Greenhouse Gas R\&D Programme in Santa Cruz, California. In the next quarter, we will further process the Sleipner data to prepare it for later inversion, and continue investigating alternative methods for calculating properties of oil/brine $/ \mathrm{CO}_{2}$ systems.
\end{abstract}


TABLE OF CONTENTS

Page

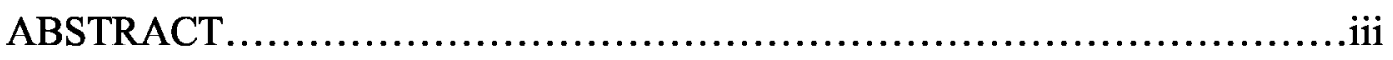

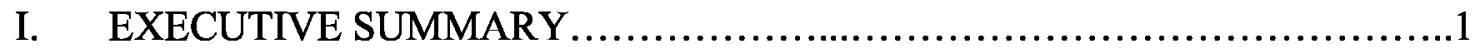

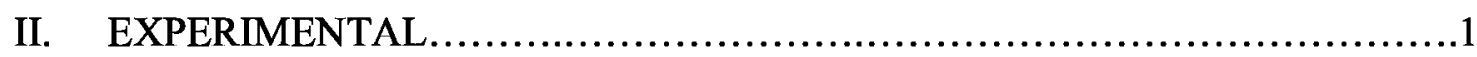

III. RESULTS AND DISCUSSION ...........................................

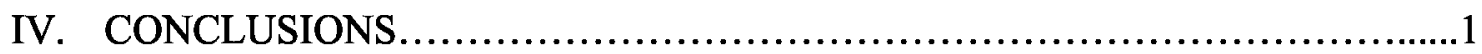




\section{EXECUTIVE SUMMARY}

In this quarter of the DOE NETL project, we have implemented an inversion algorithm that solves for changes in fluid properties over time from time-lapse seismic attributes. This algorithm constitutes the second step in the inversion procedure for Phase III of our project. We demonstrate this inversion procedure with a synthetic data example. Additional activities in this reporting period include a trip by the Principal Investigator to an International Monitoring Workshop sponsored by the IEA Greenhouse Gas R\&D Programme in Santa Cruz, California. In the next quarter, the Sleipner data will be further prepared for later inversion, and alternative methods for calculating properties of oil/brine/ $\mathrm{CO}_{2}$ systems will continue to be investigated.

\section{EXPERIMENTAL}

No experimental methods were used during this reporting period.

\section{RESULTS AND DISCUSSION}

In this quarter we have continued our algorithm development for the inversion procedure of Phase III. In the initial inversion step, a forward modeling relation is established between the rock and fluid properties of the reservoir and the resulting seismic data. Once this relationship is understood, it can be inverted in the second step to yield the time-lapse changes in fluid properties that correspond to the measured changes in the seismic data. We demonstrate this inversion procedure in Appendix A with a synthetic data example. We also show examples of time-lapse seismic attributes from the Sleipner North Sea $\mathrm{CO}_{2}$ data set that will be used as input to the real-data inversion.

In addition to this activity, the Principal Investigator attended an International Monitoring Workshop sponsored by the IEA Greenhouse Gas R\&D Programme, Santa Cruz, California on November 8-9, 2004. The objectives of the meeting were to bring together the main research groups currently active in the field of $\mathrm{CO}_{2}$ monitoring, and to review the current state of the art in monitoring technology. Several discussions of the Sleipner project pointed out that current estimates of the injected $\mathrm{CO}_{2}$ volume obtained from time-lapse seismic traveltime and amplitude changes differ from actual injected amounts, indicating that further study is needed. This observation has stimulated our own research into how such estimates can be improved using our inversion technology.

\section{CONCLUSIONS}

In this quarter we have addressed the second step of the inversion algorithm for Phase III of this study, namely, the use of time-lapse seismic anomalies to invert for changes in fluid properties over time. The inversion procedure was demonstrated with a synthetic data example. Additional activities in this reporting period include a trip by the Principal Investigator to an International Monitoring Workshop sponsored by the IEA Greenhouse Gas R\&D Programme in Santa Cruz, 
California. In the next quarter, we will further process the Sleipner data to prepare it for later inversion, and continue investigating alternative methods for generating properties of $\mathrm{CO}_{2}$ fluid mixtures by equation-of-state (EOS) methods and molecular dynamics modeling. 